\title{
O DESENVOLVIMENTO DO CONCEITO DE PULSÃO DE MORTE NA OBRA DE FREUD
}

\author{
The Development of the Concept of Death Drive of in Freud's \\ Work
}

\author{
El Desarollo de el Concepto de Pulsión de Muerte en la Obra \\ de Freud
}

\section{Le Développement de le Concept de Pulsion de Mort dans L'auvre de Freud}

\begin{abstract}
Resumo
Um dos temas metapsicológicos mais essenciais à obra freudiana é a teoria pulsional. Freud desenvolveu duas teorias - a primeira consistia em uma divisão das pulsões entre pulsões do ego e pulsões sexuais, enquanto a segunda propunha a existência de uma pulsão de morte, voltada à descatexização, e uma pulsão de vida, que buscava o investimento e a unificação. Sabendo que a segunda teoria criou bases para outro entendimento da agressividade, sadismo e masoquismo, e inclusive de psicopatologia, procura-se com este trabalho levantar hipóteses sobre o que levou Freud a modificar sua primeira teoria pulsional, e, desta maneira, tentar compreender tanto as bases que deram forma à segunda teoria pulsional, quanto à própria teoria. Conclui-se que o desenvolvimento do conceito de narcisismo, que unificou as pulsões sexuais e do ego, a retomada do princípio de constância e a compreensão da existência de uma compulsão a repetição foram os elementos que levaram Freud a propor uma nova forma de organizar as pulsões. Além disso, pode-se pensar em vivências pessoais pelas quais Freud passou e que contribuíram para uma mudança de pensamento, tais quais a Grande Guerra de 1914 a 1918 e a morte de sua filha Sophie, por volta de 1920.
\end{abstract}

Palavras-chave: pulsões; pulsão de morte; pulsão de vida; narcisismo; compulsão à repetição.

\section{Abstract}

One of the most essential metapsychological issues in the Freudian work is the drive theory. Freud developed two theories - the first consisted of a division between the ego drives and sexual drives, while the second proposed the existence of a death drive which focused on decathexization, and a Life Drive, seeking investment and unification. Knowing that the second theory created foundations for a different understanding of aggression, sadism and masochism, and even psychopathology, this work aims to hypothesize about what led Freud to change his first drive theory, and, in this way, try to understand both the foundations that shaped the second drive theory and the theory itself. It is concluded that the development of the concept of narcissism, that unified the sexual and ego drives, the resumption of the principle of constancy, and the understanding of the existence of a repetition compulsion were the elements that led Freud to propose a new way of organizing drives. Moreover, one can think of personal experiences in which Freud went through that contributed to a change in his thinking, such as the Great War of 1914 to 1918, and the premature death of his daughter Sophie, which happened around 1920.

\section{Artigo Original}

\author{
Monia Karine Azevedo ${ }^{(1)}$ \\ Gustavo Adolfo Ramos Mello \\ Neto $^{(2)}$
}

1) Psicóloga. Pós-graduanda em Psicanálise Clínica pelo Núcleo de Educação Continuada do Paraná.

2) Psicólogo, pós-doutorado em Psicanálise na Université de Paris VII. Professor da Universidade Estadual de Maringá.
Recebido em: 08/07/2013

Revisado em: 15/06/2015

Aceito em: 22/06/2015 
Keywords: drives; death drive; life drive; narcissism; repetition compulsion.

\section{Resumen}

Una de las cuestiones metapsicológicas más esenciales em la obra Freudiana es la teoría de las pulsiones. Freud desarrolló dos teorías - la primera consistió en una división de las Pulsiones entre pulsiones del yo y pulsiones sexuales, mientras que el segundo propone la existencia de una pulsión de muerte, centrada em lo desinvestimiento, y una pulsión de vida, en busca de investimiento $y$ de unificación. Sabiendo que la segunda teoría crea bases para una comprensión diferente de la agresión, el sadismo y el masoquismo, y incluso la psicopatología, Este trabajo busca crear hipótesis sobre lo que llevó a Freud a cambiar su primera teoría de las pulsiones y proponer una nueva, y por lo tanto tratar de entender las bases que dieron forma a la segunda teoría de las pulsiones,y la teoría misma. Se concluye que el desarrollo del concepto de narcisismo - que unificó las pulsiones sexuales y del yo - la reanudación del principio de la constancia, y la comprensión de la existencia de una compulsión a la repetición es lo que finalmente llevó Freud a proponer una nueva forma de pensar organización de las pulsiones. Por otra parte, se puede pensar en experiencias personales de Freud que han contribuido a un cambio en el pensamiento - como la Gran Guerra de 1914 a 1918, y la muerte de su hija Sophie, alrededor de 1920.

Palabras clave: pulsiones; pulsión de muerte; pulsión de vida; narcisismo; compulsión a la repetición.

\section{Résumé}

L'un des principaux thèmes métapsychologiques le plus essentiel dans la psychanalyse est la théorie des pulsions. Freud a développé deux théories - la première consistait en une division entre les pulsion du moi et pulsion sexuelle - tandis que la seconde théorie proposait l'existence d'une pulsion de mort, responsable par le désinvestissement, et une pulsion de vie, celle-ci étant en quête d'investissements et d'unification. Puisque que la seconde théorie a créé des fondations pour une autre compréhension de l'agression, du sadisme et du masochisme, et même dela psychopathologie, ce travail cherche à comprendre ce qui a conduit Freud à abandonner sa première théorie des pulsions et à en proposer un nouvelle, et ainsi essayer de comprendre tantôt-les bases de la seconde théorie des pulsions, tantôt la théorie elle-même. On conclut que le développement de la notion de narcissisme, qui a unifié les pulsions sexuels et les pulsions du moi, la reprise du principe de constance, et la compréhension de l'existence d'une compulsion de répétition étaient ce que finalement conduit Freud à proposer une nouvelle façon de penser l'organisation de Pulsions. Qui plus est, on peut aussi penser à des expériences personnelles de Freud qui ont contribué à un changement de la pensée tel que la Grande Guerre de 1914 à 1918, et la mort de sa fille Sophie, autour de 1920.
Mots-clés: pulsions; pulsion de mort; pulsion de vie; narcissisme; compulsion de répétition.

Uma das questões metapsicológicas mais essenciais à obra freudiana é a teoria pulsional. Segundo Freud (1930/1996k), a teoria das pulsões foi a que progrediu de forma mais cautelosa e com dificuldades em sua obra. Em vários trabalhos, como em Análise de uma fobia de um menino de cinco anos (o pequeno Hans) (1909/1996c) e Sobre o narcisismo: uma introdução (1914/1996h), o autor mencionou o quanto essa teoria estava incompleta e não havia sido suficientemente explorada.

Freud, como se sabe bem, desenvolveu duas teorias das pulsões. Uma delas, conhecida como "Teoria da Libido", foi proposta, sobretudo, em As pulsões e seus destinos (1915/1996g), e a outra é desenvolvida em Além do Princípio do Prazer (1920/1996i). A primeira teoria consistia em uma divisão das pulsões entre pulsões do ego e pulsões sexuais, sendo estas, segundo o autor, voltadas para a manutenção da espécie, e aquelas à conservação do indivíduo. Em sua segunda teoria, propôs a pulsão de morte, que seria voltada à descatexização, à inanição, à diminuição da excitação; e a pulsão de vida, que buscava o investimento e a unificação.

A segunda teoria é de bastante relevância para a psicanálise freudiana, pois criou bases para outro entendimento da agressividade, sadismo e masoquismo, e inclusive da psicopatologia, o que influenciou muitos autores atuais. Dada à importância deste conceito é que se procura com este trabalho levantar as possíveis razões que levaram Freud a abandonar sua primeira teoria pulsional e propor uma nova, e assim tentar compreender tanto os alicerces que deram forma à segunda teoria pulsional quanto à própria teoria.

Para lograr esse objetivo, realizou-se uma leitura cronológica de alguns textos freudianos, aqueles relevantes ao tema, a fim de compreender o percurso histórico do conceito. Com o intuito de selecionar os textos freudianos a serem utilizados para este propósito, efetuou-se uma busca terminológica em todos os volumes da "Edição Standard Brasileira das Obras Psicológicas Completas de Sigmund Freud" de James Strachey. Alguns termos utilizados para a busca foram: pulsão, instinto, pulsão de morte, instinto de morte, pulsão de destruição, destruição, desfusão etc.

As obras selecionadas a partir desta busca foram: Projeto para uma psicologia científica (1895/1996a), Três ensaios sobre a teoria da sexualidade (1905/1996b), Análise de uma fobia de um menino de cinco anos (o pequeno Hans) (1909/1996c), A concepção psicanalítica da perturbação psicogênica da visão (1910/1996d), Formulações sobre os dois princípios do funcionamento mental (1911/1996e), Recordar, repetir e elaborar (1914/1996f), Sobre o 
narcisismo: uma introdução (1914/1996h), As pulsões e seus destinos (1915/1996g), Além do princípio do prazer (1920/1996i), O id e o ego (1923/1996j), e O mal-estar na civilização (1930/1996k).

Quanto ao percurso deste artigo, primeiramente buscase esclarecer o significado do conceito de pulsão para Freud, quais as teorias pulsionais por ele propostas e o que seria a pulsão de morte para o autor. Em seguida, discute-se sobre o caminho entre essas teorias que culminou no conceito de pulsão de morte. Neste segundo momento, que é central ao objetivo deste artigo, traz-se o questionamento de Freud sobre sua primeira teoria pulsional e a evolução do princípio da constância até a compulsão à repetição; expõem-se também alguns fatos especulativos a respeito da vida de Freud que poderiam ter influenciado no desenvolvimento deste conceito.

Por ser a psicanálise uma teoria que não se encerrou em Freud, apresenta-se brevemente ao final desta discussão a posição de alguns autores pós-freudianos a respeito da pulsão de morte, já que esta ideia tornou-se um tanto controversa no meio psicanalítico.

\section{A pulsão}

Desde o início de sua obra, Freud menciona o que mais tarde vai ser identificado como pulsão. Segundo o editor britânico de Freud, James Strachey, no prefácio de A pulsão e seus destinos (1920/1996g), as pulsões, no princípio, apareciam sob outros nomes como: "excitações", "ideias afetivas", "impulsos anelantes", "estímulos endógenos".

Em Três Ensaios sobre a teoria da sexualidade, Freud (1905/1996b) define o conceito de pulsão. Neste trabalho, esta é exposta como o representante psíquico de uma energia que leva ao movimento, ou ainda uma espécie de demanda por ação que seria feita ao psiquismo cuja fonte seria o processo excitatório em um órgão. Há aqui uma distinção entre a fonte da pulsão e o estímulo, sendo este último produzido fora do organismo e a fonte da pulsão dentro do próprio organismo. Essa pulsão, ao contrário do estímulo, não poderia ser eliminada, sendo, pois, contínua, e exigiria que o organismo lidasse com ela.

Neste primeiro momento, portanto, Freud (1905/1996b) acreditava que todas as pulsões levavam ao movimento, e nesse mesmo trabalho fala da pulsão sexual e atribui à sua energia o nome de libido. Também faz menção a pulsões "de fome", que, em contrapartida, se relacionariam à necessidade de nutrição.

Em $O$ Pequeno Hans, encontra-se a discussão sobre uma possível terceira pulsão: a pulsão agressiva. Segundo Freud (1909/1996c), tal pulsão teria sido aventada por Adler, e ele discorda desta ideia, ao menos a essa altura de sua teoria, e dá uma explicação distinta à agressividade: Cada pulsão teria o poder de se tornar agressiva.
Em 1910, em A concepção psicanalítica da perturbação psicogênica da visão, a pulsão, chamada por ele de pulsão de fome, é efetivamente contraposta à pulsão sexual, e a ela é atribuída o status de pulsão de autopreservação ou pulsão do ego - "como disse o poeta, todos os instintos orgânicos que atuam em nossa mente podem ser classificados como 'fome' ou 'amor'" (Freud, 1910/1996d, p. 224).

Parece ser somente em 1915, após expor várias vezes a sua insatisfação com o conhecimento produzido até então a respeito do assunto ${ }^{1}$, que Freud $(1915 / 1996 \mathrm{~g})$ cria de fato uma teoria das pulsões expondo-a no trabalho $A$ pulsão $e$ seus destinos. Contudo, ele modificaria esta teoria cinco anos mais tarde quando passa a compreender outra classe de pulsões.

\section{Primeira Teoria Pusional}

Como dito anteriormente, em um primeiro momento Freud acreditava que todas as pulsões consistiam em movimento psíquico, pois seriam decorrentes de um quantum de energia que impelia o psiquismo à ação. $\mathrm{O}$ pai da psicanálise nem mesmo tentou propor quais seriam as possíveis pulsões existentes, mas acreditava que se dividiam em dois grandes grupos: autopreservação e sexuais.

As pulsões de autopreservação, entendia Freud (1915/1996g), tinham a função de preservar a existência do indivíduo, do ego, enquanto as pulsões sexuais se esforçavam na busca de objetos com vistas à preservação da espécie e a satisfação sexual. Segundo ele, a princípio as pulsões sexuais estariam ligadas às de autopreservação, e por isso buscariam vinculação, satisfação, com aquilo que preservaria a vida.

Antes mesmo de expor essa teoria, Freud já mostrava inquietação quanto à classificação dualista perdurar, e mostrava que essa teoria seria mantida até quando se mostrasse útil, ou até quando as experiências clínicas não mostrassem evidências contrárias.

Propus que se distingam dois grupos de tais instintos primordiais: os instintos do ego, ou autopreservativos, e os instintos sexuais. Mas essa suposição não tem status de postulado necessário, ela não passa de uma hipótese de trabalho, a ser conservada apenas enquanto se mostrar útil, e pouca diferença fará aos resultados do nosso trabalho de descrição e classificação se for substituída por outra. (Freud, 1915/1996g, p.139)

1 Freud, 1909/1996c, p.126; Freud 1914/1996h, p.90; Freud 1915/1996g, p.139. 


\section{Segunda Teoria Pusional}

Em 1920, Freud (1920/1996b) revê a divisão inicial que havia feito das pulsões - em pulsões sexuais e de autopreservação. Em Além do princípio do prazer, propõe a existência de uma nova dualidade na vida psíquica, a de que existem duas forças opostas: uma energia que impele à ação e outra que leva à inanição.

Aquelas que levam à ação já eram bem conhecidas, pois consistiam no agrupamento das pulsões sexuais e de autopreservação. Freud deu-lhes o nome de Pulsões de Vida. $\mathrm{O}$ autor dizia que estas pulsões diziam respeito às excitações que induziriam à busca de objetos. Por outro lado, aquelas que levavam à estagnação era a grande novidade da proposta, e Freud as nomeou Pulsões de Morte. Estas eram descritas como as que buscariam a paz, ou seja, a ausência de estimulação no organismo (Freud, 1920/1996b).

A pulsão de morte era entendida por Freud (1920/1996b) como uma tendência que levaria à eliminação da estimulação do organismo. Assim, o trabalho dessa pulsão teria como objetivo a descarga, a falta do novo, a falta de vida, ou seja, a morte. Então, o organismo não teria em sua base constitucional o desejo pela mudança, pois estaria fadado a buscar sempre estados anteriores. A tendência do organismo à mudança e ao progresso seria, portanto, uma aparência enganadora. A verdade é que o organismo estaria apenas a buscar um objetivo antigo por caminhos novos, isto é, por conta da pressão de forças perturbadoras externas, o organismo precisaria fazer um "détour" da função conservadora para lograr a meta final de conservação de estados antigos, aí é nesse "détour" que se encontra o desenvolvimento. Como diria Freud (1920/1996b): "Esses tortuosos caminhos para a morte, fielmente seguidos pelos instintos de conservação, nos apresentariam hoje, portanto, o quadro dos fenômenos da vida" (p. 49).

Em O Ego e o Id, Freud (1923/1996j) afirma que a pulsão de vida precisa encontrar formas de manter a vida ante a tendência à mortífera da pulsão oposta. Uma das soluções pontuadas por ele é o desviar da pulsão de morte para fora do organismo para não provocar a destruição interna. Assim, boa parte desta pulsão se voltaria para o exterior e se apressentaria aí, pelo menos parcialmente, em forma de destruição.

Quanto à parte da pulsão de morte que permanece no ego, Freud (1923/1996j) dizia que ela poderia chegar à descarga por meio da fusão à pulsão de vida também. Neste formato, formas saudáveis de descarga são desenvolvidas em contrapartida às soluções que a pulsão de morte encontra quando desfusionada, que seria o estabelecimento de neuroses graves. Quando desfusionada, a pulsão de morte encontraria no superego um aliado e seria a responsável pela dureza e crueldade exibida dessa instância, e também por uma ação exagerada e excessivamente punidora voltada ao ego. A pulsão de morte é responsável ainda pelo sentimento de culpa instalado no ego, que faz com que o sujeito se julgue merecedor de sofrimento.

Freud (1930/1996k) conclui que "quanto mais um homem controla a sua agressividade para com o exterior, mais severo - isto é, agressivo - ele se torna em seu ideal do ego" (p. 66), ou seja, maior a inclinação do seu ideal do ego para a agressividade contra o seu ego.

Lembra-se do que Freud defendeu em 1923 sobre a pulsão de morte, ele já havia se deparado antes e resistiu em reconhecer. Em O Pequeno Hans, Freud (1909/1996c) dizia "não posso convencer-me a aceitar a existência de um instinto agressivo especial ao lado dos instintos familiares de autopreservação e de sexo, e de qualidade igual a destes" (p. 125), e mais tarde justifica tal resistência pela dificuldade que a criança interna tem de aceitar "a inata inclinação humana para a 'ruindade', a agressividade e a destrutividade, e também para a crueldade" (Freud, 1930/1996k, p. 124).

Nos trabalhos finais, Freud (1930/1996k) também reconhece que a pulsão de morte se tornou-uma das teorias mais úteis do ponto de vista teórico do que qualquer outra. Veja-se um pouco sobre algumas questões que se acredita estar relacionadas à proposição desta nova pulsão.

\section{O caminho entre as teorias pulsionais}

Como dito anteriormente, apesar de Freud ter proposto duas teorias pulsionais, a segunda teoria - que trata de pulsão de vida e de morte - não descarta o que é proposto na primeira - pulsões sexuais e de autoconservação. Apenas agrupa as pulsões sexuais e de autopreservação nas pulsões de vida. Assim, antes de tudo, uma questão a ser levantada é: o que levou Freud a agrupar num mesmo conjunto as pulsões do ego e sexuais?

\section{Questionamento da primeira dualidade pulsional: sobre o narcisimo}

Freud (1920/1996b) agrupa as pulsões sexuais e do ego no trabalho Além do princípio do prazer sob o signo das pulsões de vida, porém as ideias que deram base para tal são anteriores. Em 1914, antes mesmo de discorrer mais profundamente sobre a sua primeira teoria das pulsões, Freud trata desse possível agrupamento no trabalho Sobre o Narcisismo: uma introdução.

Neste último trabalho, Freud (1914/1996h) desenvolve uma ideia que começou a chamar-lhe a atenção a partir dos estudos sobre a esquizofrenia ou demência precoce. $\mathrm{O}$ autor, que procurava articular a teoria da libido a estas patologias, percebeu que nestas ocorria à retirada de investimentos do mundo externo e o investimento no eu. A 
esta atitude, de "tratar o seu próprio corpo da mesma forma pela qual o corpo de um objeto sexual" (p. 84), deu o nome de narcisismo, e a considerou como, em certa medida, algo que se pode atribuir a todo ser humano.

Até então Freud acreditava que, em função do ego, agiam as pulsões de autopreservação (ou do ego), e do mundo externo, as pulsões objetais (ou sexuais). Entretanto, com o entendimento de que as pulsões objetais podiam ser recolhidas do mundo externo e investidas no próprio ego, ele pergunta se não se trataria, no que tange ambas as pulsões, de uma única energia a atuar na mente. Assim, o autor passa a considerar a existência de uma libido do ego que só posteriormente é dirigida a objetos. Freud (1914/1996h) fala, então, de um estado primário, que ele denomina narcisismo, no qual a libido sexual e do ego seriam uma única, e esta energia estaria investida unicamente no próprio ego. Somente mais tarde, quando a passasse a existir investimento objetal, seria possível diferenciá-las.

(...) a descoberta de que o próprio ego se acha catexizado pela libido, de que o ego, na verdade, constitui o reduto original dela e continua a ser, até certo ponto, seu quartelgeneral. Essa libido narcísica se volta para os objetos, tornando-se assim libido objetal, e podendo transformarse novamente em libido narcísica (Freud, 1930/1996k, p. 122).

Segundo Ernest Jones (1961), biógrafo de Freud, em sua obra, o criador da psicanálise era cativado pela ideia de um profundo conflito na mente entre forças opostas - uma tendência dualista. Assim, parecia-lhe insatisfatório explicar o conflito psíquico como conflito entre duas tendências da mesma pulsão.

Mesmo assim, apesar desta compreensão que mostra a possibilidade de agrupamento das pulsões, Freud mantém a distinção entre estas pulsões do ego e objetais. O autor defende que as pulsões, apesar de originárias de uma mesma energia, refletem bem a função dúplice que o indivíduo tem: de servir suas próprias finalidades e a outra de servir a algo maior, a preservação da espécie.

Apesar de que no trabalho referido Freud mantém tal postura, um ano depois ele apresenta em A pulsão e seus destinos (1920) esta sua teoria pulsional que passou a ser conhecida como Teoria da Libido, mas já deixa claro de antemão que caso o trabalho psicanalítico viesse a produzir uma nova hipótese mais útil, estaria disposto a abandonar esta teoria.

Com a semente plantada sobre uma única vertente originária para as pulsões do ego e sexuais, pode-se partir para outro ponto: a construção do conceito de pulsão que se contrapõe à pulsão de vida ou libidinal. Para que houvesse uma pulsão de vida, foi necessário construir-se uma pulsão de morte. Porém, como isto se deu?

\section{Princípio da inércia e da constância: base para a pulsão de morte}

A ideia de uma pulsão de morte se desenvolveu ao longo da teoria freudiana de forma paulatina. Desde Projeto para uma psicologia cientifica Freud (1996/1895h) estabelece as bases para o que seria reconhecido posteriormente como a pulsão de morte. Nesse trabalho, em que o autor buscava uma forma neurológica de explicar o funcionamento do aparelho mental, ele fala da existência de um quantum que circula e movimenta o aparelho mental e de uma tendência desse aparelho para reduzir, ou controlar esta quantidade.

No que tange à tendência para reduzir ou controlar este quantum, Freud (1895/1996a) apresenta o princípio da inércia e o da constância. $\mathrm{O}$ autor discute que há um princípio "de inércia neuronal" em que os "neurônios tendem a se livrar de Q", sendo Q uma quantidade de estímulo (p. 348). Livrar-se da quantidade, ou seja, manter Q a zero, consistiria em uma função primária do sistema nervoso, e que o organismo teria, na verdade, que abandonar. $\mathrm{O}$ organismo precisaria se acostumar a suportar uma carga de Q, oriunda das estimulações endógenas, para então poder satisfazer as exigências de vida. Isto não quer dizer que o princípio de inércia é completamente abandonado, mas que é modificado. $\mathrm{O}$ organismo passa, assim, a buscar manter constante a quantidade de energia interna.

Apesar de a teoria acima ser neurológica, ela serve de base para uma teoria de funcionamento do aparelho psíquico proposto em Além do Princípio do Prazer, em 1920. A quantidade Q proposta no "Projeto" seria posteriormente identificada com a Pulsão de vida, descrita como uma pulsão de movimento, moção; e a tendência a livrar-se de tal Q, como a pulsão de morte, ou de inanição. Num primeiro momento, tem-se, então, uma teoria neurológica e, posteriormente, tal teoria evoluiu até a ideia de pulsões de vida e de morte.

Em A pulsão e seus destinos (1915), tal compreensão dualista - de uma quantidade que levaria ao movimento, de um lado, e uma tendência a livrar-se de tal quantidade, de outro - já se desprende do "neurologismo" e é compreendida como um modus operandi do aparelho psíquico. Apenas, ainda, não adquirem status de pulsões opostas.

Neste último artigo, Freud (1915/1996g) retoma o princípio da constância e a ideia de que o trabalho do sistema nervoso seria a manutenção dos estímulos no nível mais baixo possível e, assim, atribui ao sistema nervoso a tarefa de dominar estímulos. Ainda, considera como pulsão os estímulos que se originam dentro do organismo e criam tensão, e a tendência a reduzir estes estímulos não adquire o status de uma pulsão, mas, ainda, apenas de uma função do aparelho mental. Estas pulsões eram aqui divididas entre Pulsões do ego e Pulsões sexuais - primeira teoria da pulsão. 
Duas coisas são claramente expostas em A pulsão e seus destinos, e, neste momento, sem caráter neurológico ou, pelo menos, inteiramente neurológico. Primeiro a tendência do organismo a dominar os estímulos - isto dá base para a construção posteriormente da compulsão a repetição, haja vista que esta busca dominar as pulsões. Por último, as duas tendências opostas do organismo: uma que busca diminuir a tensão e a energia proveniente das pulsões, e outra que trata de um fluxo constante de energia.

Freud só vai atribuir o status de pulsão ao princípio da constância e aos processos a ele associados, em 1920, em Além do Princípio do Prazer. Nesse trabalho, retoma a ideia já proposta em A pulsão e seus destinos (1915) de que o aparelho mental visa dominar estímulos. Porém, devido aos seus recentes estudos sobre sonhos sujeitos que sofrem neuroses traumáticas, entre outros, esta tendência do organismo tomou novas proporções, pois Freud compreendeu tal tendência como algo básico e fundamental do psiquismo, de forma tal que afirmava que "o objetivo de toda vida é a morte" (Freud, 1915/1996g, p. 49), e que a tendência do organismo à mudança e ao progresso é, na verdade, uma aparência enganadora.

Veja-se algo agora acerca do que contribuiu para que neste trabalho o princípio da constância acabasse por tomar tamanhas proporções.

\section{Compulsão à repetição}

É possível pensar que a retomada e nova elaboração do princípio da constância neste momento da teoria encontram alguma explicação na origem de outro conceito psicanalítico que passou a ocupar os pensamentos de Freud desde 1914: a compulsão à repetição.

Em Recordar, repetir e elaborar, quando Freud (1914/1996f) discorre a respeito da técnica psicanalítica e do trabalho da psicanálise e fala em recobrar os conteúdos reprimidos como forma de lograr avanços terapêuticos, o autor depara-se com observações clínicas que dão indícios de que existem conteúdos que não podem ser recordados e, portanto, não se apresentam como lembranças e acabam por surgir como atuação, ou seja, serem repetidos nas ações. Nesse trabalho, então, Freud chama a atenção para uma tendência do paciente em terapia a repetir conteúdos, mesmo os que trariam sofrimentos e que levassem à patologia.

Em tal momento, Freud ainda não chama atenção para uma espécie de "incoerência" no funcionamento mental que se instalava com essa tendência a repetir, o que faz somente em Além do Princípio do Prazer, quando retoma essa ideia da compulsão a repetir.

A "incoerência" dizia respeito ao fato de que repetir conteúdos de sofrimento, patológicos, ou seja, desprazeirosos, implicava em desconsiderar outra tendência do psiquismo que Freud havia reconhecido tempos atrás como soberana, em Formulações sobre os dois princípios do funcionamento mental (1911), uma tendência do psiquismo a evitar o desprazer, conhecido como o Princípio do prazer.

Então, em Além do Princípio do Prazer, Freud (1920/1996i) fala do quanto isso o estava intrigando. $\mathrm{O}$ autor percebeu que, por vezes, ao invés de reduzir a carga de energia, como prezava o princípio do prazer, o psiquismo buscava o contrário: aumentar a carga, o que gerava desprazer. Freud entendeu que a tendência a repetir conteúdos desprazeirosos, e assim aumentar a carga psíquica, entrava em contradição com o princípio do prazer, mas passou a analisar e perceber que, na verdade, tratava-se de algo que, em seu fim maior, buscava realizar um trabalho para que o princípio do prazer pudesse vir a entrar em cena.

Após analisar tal ideia, Freud (1920/1996i) explica que o psiquismo traz à tona conteúdos que nunca foram prazerosos, que despertariam o desprazer por aumentar o quantum de energia. O que o psiquismo aí busca é, pois, uma forma de "domar" esses conteúdos e, assim, lograr a constância, o equilíbrio mental. Entende-se que a excitação excessiva é traumatizante e precisa ser dominada para que não se mantenham níveis internos muito altos que venham a causar um enlouquecimento absoluto. Somente após ter sido efetuada essa tarefa é que seria possível a ação do princípio do prazer.

É disso, pois, que o autor trata quando fala acerca dos já mencionados sonhos nas neuroses traumáticas. Freud (1920/1996i) questionava-se porque sonhos desprazeirosos que aumentavam a carga de excitação psíquica eram trazidos à tona pelo psiquismo ao invés de evitados. A resposta que o criador da psicanálise encontrou foi que os conteúdos traumáticos, desprazeirosos, eram revividos em uma tentativa do psiquismo de dominar a energia relacionada a eles, ou seja, vincular ao psiquismo os conteúdos traumáticos e devolver a paz e o equilíbrio ao psiquismo. Conclui que tais sonhos só poderiam estar "ajudando a executar outra tarefa, a qual deve ser realizada antes que a dominância do princípio de prazer possa começar" (p. 42).

Outro exemplo que Freud (1920/1996i) analisava nesse âmbito era a brincadeira das crianças, que pareciam divertirse em recriar as situações angustiantes da vida real nestas atividades, como, por exemplo, a sua separação da mãe, como é o célebre caso de seu neto Ernst ao brincar com um carretel. $\mathrm{O}$ autor percebeu que a satisfação se dava por essas crianças conseguirem diminuir o seu desprazer pela vinculação da energia que levava à experiência de desprazer. Através destas observações, Freud veio a supor que haveria uma tendência do organismo à repetição, e que esta seria uma forma de vincular psiquicamente a energia que estaria solta em seu interior e assim dominá-la, isto é, transformála em algo familiar e não traumatizante. Ao transformar este algo em "familiar", o equilíbrio e constância seriam recobrados. A repetição de situações anteriores permitia 
ao sujeito dominar os estímulos e, deste modo, obter cada vez mais vivências cada vez menos traumatizantes. Desta forma, seria possível reviver algo seguro e conhecido que não colocaria o organismo em cheque, que não o desafiaria, e que o permitiria manter a constância e o equilíbrio.

Assim, essas experiências clínicas e a análise dos sonhos traumáticos fizeram Freud retomar a ideia da busca do organismo pela constância, já que sua nova descoberta, a compulsão à repetição, também estava a serviço desse princípio.

Desta forma, Freud está novamente frente à tendência do organismo de buscar a inanição, a ausência de excitação, a morte. Porém, desta vez, toma tal tendência do organismo como algo mais significativo, tanto por tê-lo percebido como algo bastante fundamental ao psiquismo, como também por tal tendência opor-se fundamentalmente à concepção das pulsões do ego e objetais, já que estas falavam de movimento, de investimento, de catexia, enquanto aquela dizia respeito a diminuir todo o esforço com vistas a obter o equilíbrio e a ausência de excitação.

\section{Momentos históricos}

Até aqui se realizou um percurso nos trabalhos de Freud, buscando identificar no desenrolar da teoria como a ascensão da pulsão de morte se deu - quais foram os questionamentos e inconsistências teóricas que levaram o autor e propor não apenas um novo conceito, mas uma nova divisão na teoria. Apesar de não ser o objetivo maior deste trabalho, a busca por possíveis razões históricas e pessoais que levassem à proposição do conceito de pulsão de morte, traz-se aqui brevemente, e mais a título de especulação, alguns eventos que são concomitantes ao surgimento do conceito.

O biografo de Freud Ernest Jones aponta que algumas experiências de Freud poderiam ter contribuído para que surgisse uma discussão sobre uma tendência do organismo a buscar a morte. Segundo Jones (1961), Freud teria enfrentado um período de depressão, e que segundo algumas pessoas isto teria desencadeado seus pensamentos acerca da morte. A depressão poderia ser decorrente de perdas que Freud sofrera já que dois anos depois do fim da guerra, no início de 1920, ele passa por duas perdas pessoais significativas: seu amigo Von Freund e sua jovem filha Sophie, que falece, inesperadamente, de pneumonia. O biógrafo, contudo, diz que existem indícios de que a depressão poderia ter originado quando ela ainda era viva.

Antes destas perdas, Freud já enfrentara situações relacionadas à morte. Uma delas diz respeito à participação de seus filhos na Primeira Guerra Mundial (1914-1918). Segundo Jones (1961), Freud preparava-se para uma eminente perda de seus filhos, o que, contudo, não veio a acontecer. Outra questão relevante trazida por Jones (1961), é que no final dos anos 10 Freud mostrava-se confiante de que em breve morreria. Sua morte teria mesmo uma data embasada em crenças supersticiosas; acreditava que morreria em 1918. Em uma carta que envia neste período a Eitingon diz que "já tenho direito de pedir que, quando chegue à ocasião, enterrem-me sem oração fúnebre alguma" (Freud, citado por Jones, 1961, p. 200, tradução nossa). De acordo com o biógrafo, em torno de 1915, tomado esta sensação de morte eminente, Freud escreveu uma série de obras sintéticas e outras mais clarificadoras sobre a metapsicologia psicanalítica.

A guerra por si só também pode ter contribuído para os pensamentos de Freud sobre a morte. Segundo Jones (1961), a guerra trouxera evidências da agressividade humana, o que poderia, por sua vez, ter influenciado Freud a consolidar suas ideias sobre a pulsão de morte, já que um dos argumentos que utilizava para sustentá-la seria a existência de uma destrutividade inerente ao ser humano. Além disto, houve também respingos da guerra nas práticas profissionais de Freud. Começam a surgir em 1920 uma série de queixas acerca do tratamento dado aos afetados por neuroses de guerra e Freud passou a estudar tal fenômeno, que desemboca no seu trabalho Além do Princípio do Prazer.

\section{Pulsão de morte entre os pós-freudianos}

A segunda teoria pulsional é uma das teorias mais controversas da metapsicologia psicanalítica. Segundo Roudinesco e Plon (1998), tal teoria gerou enorme repercussão e rejeição dentro da psicanálise, com alegações da falta de embasamento empírico para a existência de uma pulsão de morte. Houve teóricos que se debruçaram sobre este conceito apresentando reformulações e ou acréscimos, como é o caso de Jean Laplanche, André Green, Melanie Klein etc., e outros que não aderiram a esta ideia freudiana, como é o caso de Winnicott.

Laplanche (1988), criador da Teoria da Sedução Generalizada (TSG), é um dos autores que mantém o conceito de pulsão de morte e apenas reelabora alguns pontos que, segundo ele, haviam ficado em aberto na segunda teoria pulsional proposta por Freud. O autor argumentava que Freud falava de um dualismo das pulsões, mas não de um dualismo energético, ou seja, haveria apenas uma energia, a libido, que movimentaria o aparelho psíquico, pois Freud nunca postulou uma energia equivalente à libido para a pulsão de morte - uma destrudo. Para o autor, essa questão é solucionada a partir da concepção de que toda pulsão é, na verdade, sexual.

Para Laplanche (1988), o que foi atribuído por Freud à pulsão de morte era, na verdade, pertinente à pulsão sexual, e foram delas desconectadas após a descoberta do narcisismo. Segundo o autor, em um primeiro momento, 
Freud entendia que "somente a sexualidade tem o direito de se nomear pulsão; o único conteúdo do inconsciente é a sexualidade" (p. 20); em seguida, com a descoberta do narcisismo, uma compreensão da sexualidade pelo aspecto do amor; e, por fim, a sexualidade ligando-se a conservação do objeto, e deixando seu aspecto desligado à pulsão de morte. A partir desta construção, Laplanche (1988) argumenta que "algo se perdeu", e este algo seria o caráter não-ligado da sexualidade. A ligação, construção, síntese, totalidade etc., ou seja, Eros ficou vinculado à pulsão de vida na nova teoria pulsional.

Porém, segundo Laplanche (1988), Eros é só uma parte das pulsões sexuais. As pulsões sexuais de vida são as pulsões sexuais ligadas, que buscam a totalidade, a construção, a síntese; buscam manter constante a pulsão; já as pulsões sexuais de morte têm por fim a descarga total da pulsão, e a desunião. Segundo Laplanche (1993/1997, citado em Netto; Cardoso, 2012), a pulsão de morte, seria, na verdade, os aspectos "menos narcísicos e mais desestruturantes, fragmentados e fragmentadores da pulsão" (p.535), ainda "o que chamo 'pulsão de morte' é a sexualidade infantil funcionando de modo puramente anárquico" (2007b, citado em Netto; Cardoso, 2012, p. 536).

Winnicott, por outro lado, é um dos psicanalistas pósfreudianos que não aderiram ao conceito de pulsão de morte. Segundo Fulgêncio (2009), para ele não haveria uma pulsão de destruição agindo lado a lado à pulsão sexual, e que tal proposição teria sido um erro cometido por Freud. O autor rebate tanto a compulsão a repetição quanto a agressividade como suportes para a existência de uma pulsão de morte.

Segundo Fulgêncio (2009), para Winnicott tomar a tendência à descarga como um argumento à existência de uma busca natural do organismo para a morte seria incorreto. Esta tendência seria apenar a tentativa de "colocar o que foi vivido dentro da sua área de controle onipotente, ou seja, de poder experienciar aquilo que está cindido nele, integrando esse não-vivido" (p. 478), e assim o amadurecimento poderia prosseguir, e não uma disposição do organismo para a morte, como dissera Freud.

Outro argumento sustentado por Freud e rebatido por Winnicott seria a suposta inclinação humana para a agressividade. Para este último autor, não faria sentido à destruição pela destruição. A agressividade existiria como uma força vital, e alcançaria o patamar de destrutividade de forma não intencional, mas como decorrência da expansão individual ou como defesa - a destrutividade não seria inerente ao indivíduo, mas uma defesa decorrente de algum dano causado a si (Ferreira, 2008).

\section{Considerações finais}

O conceito de pulsão de morte tornou-se, para muitos, bastante útil do ponto de vista teórico, pois a partir dele pensou-se ser possível compreender questões como a agressividade, autodestruição, culpa, e mesmo entender fenômenos como as psicopatologias contemporâneas. Buscou-se com este trabalho compreender o que levou Freud a propor a teoria pulsional que abarca este conceito de Pulsão de Morte, e abandonar sua primeira teoria pulsional - Teoria da Libido. Chegou-se à conclusão de que algumas descobertas teóricas fizeram com que esta teoria fosse substituída por uma nova.

Numa primeira perspectiva estão as descobertas que levaram ao questionamento da primeira teoria das pulsões. Entre elas se destaca principalmente o trabalho Sobre o Narcisismo: uma introdução (1914), em que o autor propõe que o próprio ego se acha catexizado pela libido, de forma que a energia das pulsões do ego, e não apenas das pulsões objetais, seria libidinal. Essa descoberta levou Freud a pensar que haveria apenas um tipo de pulsão, a libidinal, o que the era muito incômodo, pois não the pareceu interessante explicar o conflito psíquico entre duas tendências de uma mesma pulsão. Em segundo está à evolução de ideias presentes desde o princípio da obra de Freud e que serviram de base para a nova postulação. Uma dessas ideias é o do Princípio da Constância, que já era defendido por Freud desde Projeto para uma psicologia científica (1895). Outra é a ideia de compulsão à repetição, que Freud começa a pensar em 1914 no seu trabalho Recordar Repetir e Elaborar. Também, pode-se pensar em vivências pessoais pelas quais Freud passou e que, especula-se, possam ter contribuído para uma mudança de pensamento - de um lado está a Grande Guerra, de 1914 a 1918; de outro, a morte de sua filha Sophie.

Observou-se que este conceito não foi aceito unanimemente entre os pós-freudianos. Enquanto alguns o utilizaram para explicar fenômenos como a agressividade, acrescentando ou modificando alguns preceitos; outros negaram completamente sua existência atribuindo diferentes explicações a questões como a compulsão a repetição e a agressividade.

\section{Referências}

Ferreira, F. P. (2008). Pulsão e relação de objeto no pensamento psicanalítico contemporâneo. Tese de doutorado, Pontifícia Universidade Católica, Rio de Janeiro.

Freud, S. (1996a). Projeto para uma psicologia científica. In J. Strachey, Edição Standard Brasileira das Obras Psicológicas Completas de Sigmund Freud (Vol. 1). 
Rio de Janeiro: Imago. (Originalmente publicado em 1895)

Freud, S. (1996b). Três ensaios sobre a teoria da sexualidade. In J. Strachey, Edição Standard Brasileira das Obras Psicológicas Completas de Sigmund Freud (Vol. 7). Rio de Janeiro: Imago. (Originalmente publicado em 1905).

Freud, S. (1996c). Análise de uma fobia de um menino de cinco anos (o pequeno Hans). In J. Strachey, Edição Standard Brasileira das Obras Psicológicas Completas de Sigmund Freud (Vol. 10). Rio de Janeiro: Imago. (Originalmente publicado em 1909)

Freud, S. (1996d). A concepção psicanalítica da perturbação psicogênica da visão. In J. Strachey, Edição Standard Brasileira das Obras Psicológicas Completas de Sigmund Freud (Vol. 11). Rio de Janeiro: Imago. (Originalmente publicado em 1910)

Freud, S. (1996e). Formulações sobre os dois principios do funcionamento mental. In J. Strachey, Edição Standard Brasileira das Obras Psicológicas Completas de Sigmund Freud (Vol. 12). Rio de Janeiro: Imago. (Originalmente publicado em 1911)

Freud, S. (1996f). Recordar, repetir e elaborar. In J. Strachey, Edição Standard Brasileira das Obras Psicológicas Completas de Sigmund Freud (Vol. 12). Rio de Janeiro: Imago. (Originalmente publicado em 1914).

Freud, S. (1996g). A pulsão e seus destinos. In J. Strachey, Edição Standard Brasileira das Obras Psicológicas Completas de Sigmund Freud (Vol. 14). Rio de Janeiro: Imago. (Originalmente publicado em 1915)

Freud, S. (1996h). Sobre o narcisismo: uma introdução. In J. Strachey, Edição Standard Brasileira das Obras Psicológicas Completas de Sigmund Freud (Vol. 14). Rio de Janeiro: Imago. (Originalmente publicado em 1914)

Freud, S. (1996i). Além do princípio do prazer. In J. Strachey, Edição Standard Brasileira das Obras Psicológicas Completas de Sigmund Freud (Vol. 18). Rio de Janeiro: Imago. (Originalmente publicado em 1920)

Freud, S. (1996j). O id e o ego. In J. Strachey, Edição Standard Brasileira das Obras Psicológicas Completas de Sigmund Freud (Vol. 19). Rio de Janeiro: Imago. (Originalmente publicado em 1923)

Freud, S. (1996k). O mal-estar na civilização. In J. Strachey,
Edição Standard Brasileira das Obras Psicológicas Completas de Sigmund Freud (Vol. 21). Rio de Janeiro: Imago. (Originalmente publicado em 1930)

Fulgencio, L. (2012). Críticas e alternativas de Winnicott ao conceito de pulsão de morte. Ágora: Estudos em Teoria Psicanalítica, 15(spe), 469-480.

Jones, E. (1961). Vida y obra de Sigmund Freud. Barcelona: Editorial Anagrama.

Laplanche, J. (1988). A pulsão de morte na teoria da pulsão sexual. In. A. Green, P. Ikonen, J. Laplanche, E., Rechardt, H., Segal, D. Widlöcher. et al. A pulsão de morte. (p. 11-28). São Paulo: Escuta.

Netto, N.K.P., \& Cardoso, M.R.(2012). Sexualidade epulsão: conceitos indissociáveis em psicanálise? Psicologia em Estudo, 17(3), 529-537.

Roudinesco, E., \& Plon, M. (1998). Dicionário de psicanálise. Rio de Janeiro: Jorge Zahar.

\section{Endereço para correspondência:}

Monia Karine Azevedo

Endereço: Av. Mauro Mori, $\mathrm{n}^{\circ}$ 475, Centro. Goioerê/PR. CEP: 87360-000

E-mail: monia_azevedo@hotmail.com

\section{Endereço para correspondência:}

Gustavo Adolfo Ramos Mello Neto

Endereço: R. Professor Ney Marques, $\mathrm{n}^{\circ}$ 21, Jardim

Universitário. Maringá/PR. CEP: 87020-300.

E-mail: garmneto@gmail.com 